Stephen D. Silberstein, M. Alan Stiles, William B. Young (eds.)

Atlas of Migraine and Other Headaches, ed. 2

Taylor \& Francis, London 2005

140 pp.; GBP 60.00

ISBN 1-84214-273-9

The aims of the editors of this short volume, as described in the preface, are on the one hand to approach the huge problem of headache from a visual perspective and on the other to provide a better understanding of the complex underlying mechanism which might eventually result in better care for the patients. Needless to say that to reach that goal in less than 150 pages would be quite an achievement!

Under the direction of Prof. S.D. Silberstein, Director of the Jefferson Headache Center (JHC), with the help of Associate Prof. W. Young, Director of the Inpatient Program at the JHC, and the expertise of Dr. M.A. Stiles, an orofacial pain specialist, the authors embark on a journey to reveal to us what is hidden behind the symptomatology of headaches. The first chapter deals with headaches in history from the ancient to the present world with graphic representations of treatments (trepanation among others...), eminent physicians who described headaches and migraine in particular, and advertisements. It ends with a gallery of famous migraine sufferers ranging from Julius Caesar, Blaise Pascal, Napoleon I and Lewis Carroll to Virginia Woolf or even very recently the actress Whoopi Goldberg. After these first interesting pages, the reader is presented with the International Classification of Headache Disorders (2004) in its shorter form. What would have been useful in its detailed version becomes redundant as it is. Interesting facts are then provided in the third chapter that covers epidemiology. The authors remind us that we are not equal as far as headache is concerned. Indeed, the 40-year-old Caucasian female with a low income and suffering either from stroke, epilepsy, depression, mania or anxiety remains the most likely to develop a migraine. In the USA, productivity loss due to migraine alone is enormous, with USD 13 billion annually. Finally, migraine and associated conditions such as epilepsy, stroke and psychiatric disorders are quickly described. The fourth chapter covers the pathophysiology of headache with clarity, up-to-date explanations and well-commented figures about cortical spreading depression, the role of nociceptors located in the trigeminal nucleus caudalis and research opportunities due to the constant progress of functional imaging techniques (e.g. positron emission tomography). Each of the following three chapters focuses on specific types of headache which are migraine, trigeminal autonomic cephalalgias and tension-type headache. All but the last are discussed thoroughly using either pathophysiological and anatomical diagrams or drawings depicting visual disturbances during attacks. The last chapter encompasses the vast territory of secondary headaches. The authors let the pictures speak for them- selves with 30 pages full of pictures and short comments. The text is concise, with the usual advice not to hesitate to investigate patients showing red flags - paediatric red flags are mentioned as well - but each separate pathology is listed without details. This is unfortunate as the characterisation of each headache associated with these conditions would have helped the reader. It would also have been valuable to know about the most appropriate cerebral imaging and the most efficient treatment.

All in all, the authors manage to offer varied and original illustrations of a complex entity, but are less convincing about the didactic and therapeutic aspects. It remains a stimulating read that can be recommended to residents and students.

J. Morier, Lausanne

Dilip V. Jeste, Joseph H. Friedman (eds.)

\section{Psychiatry for Neurologists}

Current Clinical Neurology

Totowa, Humana Press, 2006

444 pp.; USD 135.00

ISBN 1-58829-483-8

In the past decades new diagnostic tools - such as MRI - have arrived and the clear dichotomy between 'organic' and 'nonorganic' etiologies of psychiatric diseases is fading. Indeed neurology and psychiatry have a lot in common; not only because complex diseases such as Huntington's disease or Tourette's syndrome display both motor and behavioral symptoms, but also because both disciplines deal with brain metabolism, neurotransmitter pathways and even structural brain abnormalities. It is thus necessary for the neurologist to have an understanding of psychiatric diseases and the book by Jeste and Friedman perfectly fits this need. This comprehensive book is divided into two main parts. The first one gives a summary of the major psychiatric diagnoses such as depression, anxiety, schizophrenia, personality disorder, with diagnosis criteria, clinical course and treatment, together with an emphasis on two topics of major importance for the neurologist such as hysteria and catatonia, which are frequently encountered in neurological practice but seldom addressed in neurology textbooks. The second part, dedicated to the psychiatric complications of neurological diseases such as dementia, stroke, neuromuscular disorder, multiple sclerosis, Parkinson's disease, epilepsy, Tourette's syndrome, Huntington's disease, and psychiatry of the cerebellum, adds a practical clinical approach to certain aspects of diseases well known to neurologists.

Altogether, this book is a useful companion for the everyday practice of the neurologist, the residents, and is also of interest to medical students.

Selma Aybek, Lausanne

\section{KARGER}

() 2006 S. Karger AG, Basel

Fax +41613061234 E-Mail karger@karger.ch www.karger.com www.karger.com/ene 